\title{
No Mutations in the PSMC3IP Gene Identified in a Swedish Cohort of Women with Primary Ovarian Insufficiency
}

\author{
A. Norling $^{a, b} \quad$ A.L. Hirschberg ${ }^{b} \quad$ L. Karlsson ${ }^{a} \quad$ K.A. Rodriguez-Wallberg ${ }^{c}$ \\ E. Iwarsson ${ }^{a} \quad$ A. Wedell ${ }^{a, d} \quad$ M. Barbaro ${ }^{a, d}$
}

Departments of a Molecular Medicine and Surgery and 'bomen's and Children's Health, Karolinska Institutet, Karolinska University Hospital, and 'Department of Clinical Science, Intervention and Technology, Section for Obstetrics and Gynaecology and Fertility Unit, and d Centre for Inherited Metabolic Diseases (CMMS), Karolinska University Hospital, Stockholm, Sweden

\section{Key Words \\ Disorders of sex development · Gonadal dysgenesis . \\ Premature ovarian failure · Primary ovarian insufficiency . PSMC3IP}

\begin{abstract}
Ovarian dysfunction before the age of 40 years, characterized by hypergonadotropic hypogonadism and presenting with either primary or secondary amenorrhea, is called primary ovarian insufficiency (POI). POI has a significant genetic component, but the specific genetic cause is often unknown. A novel candidate gene for POI, PSMC3IP, has recently been identified. The aim of this study was to investigate a group of patients with POI for possible PSMC3IP mutations. Therefore, DNA samples from 50 patients with $\mathrm{POI}$ of primarily Swedish origin were used in the study, 27 with secondary amenorrhea (median age of diagnosis 23 years) and 23 with primary amenorrhea. Control material consisting of DNA samples from 95 women without POI was used for investigation of novel sequence variants. All exons and intron/exon boundaries of the PSMC3IP gene were analyzed by PCR and sequencing. As a result, no pathogenic mutation in the PSMC3IP gene was detected in the cohort. A previously un-
\end{abstract}

reported variant, NM_016556.3:c.337+33A>G, was detected in heterozygous form in 1 patient with secondary amenorrhea, likely constituting a normal variant. Two reported single nucleotide polymorphisms were detected in the cohort at the expected frequency. In conclusion, PSMC3IP gene mutations are not common causes of POI in this Swedish cohort.

(c) 2014 S. Karger AG, Basel

Primary ovarian insufficiency (POI) is the suggested term to describe ovarian dysfunction before the age of 40 years [Nelson, 2009]. This condition can present with either primary, or more commonly, secondary amenorrhea and is characterized by hypergonadotropic hypogonadism with serum FSH levels in the menopausal range [Simpson and Rajkovic, 1999; Nelson, 2009]. The suggested causative mechanisms for POI are follicle depletion or follicle dysfunction. A small number of initial germ cells, increased apoptosis, or destruction of primordial follicles cause follicle depletion, and a failure of follicles to respond to hormonal stimuli constitutes follicle dysfunction [Nelson, 2009; De Vos et al., 2010]. POI is heterogeneous, and follicle depletion can also be caused

\begin{tabular}{ll}
\hline KARGER & $\begin{array}{l}\text { @ 2014 S. Karger AG, Basel } \\
\text { 1661-5425/14/0084-0146\$39.50/0 Open carcess }\end{array}$ \\
E-Mail karger@karger.com & $\begin{array}{l}\text { This is an Open Access article licensed under the terms of the } \\
\text { Creative Commons Attribution-NonCommercial 3.0 Un- } \\
\text { ported license (CC BY-NC) (www.karger.com/OA-license), } \\
\text { applicable to the online version of the article only. Distribu- } \\
\text { tion permitted for non-commercial purposes only. }\end{array}$
\end{tabular}

Ameli Norling

Karolinska Institutet

Department of Molecular Medicine and Surgery CMM L8:02

Karolinska University Hospital, SE-171 76 Stockholm (Sweden)

E-Mail ameli.norling@ki.se 
Table 1. Patient overview

\begin{tabular}{|c|c|c|}
\hline Clinical data & $\begin{array}{l}\text { Primary } \\
\text { amenorrhea } \\
(\mathrm{n}=23)\end{array}$ & $\begin{array}{l}\text { Secondary } \\
\text { amenorrhea } \\
(n=27)\end{array}$ \\
\hline Median age at diagnosis, years & $16(13-18)$ & $23(13-37)$ \\
\hline Median age at menarche, years & - & $13(10-15)$ \\
\hline Median FSH level at diagnosis, IU/l & & \\
\hline (reference value: <30 IU/l) & $89(39-150)$ & $84(34-155)$ \\
\hline Swedish, Caucasian, n (\%) & $17(74)$ & $23(85)$ \\
\hline Known heredity for POI, n (\%) & $1(4.3)$ & $5(18.5)$ \\
\hline Spontaneous conception, n (\%) & 0 & $10(37)$ \\
\hline
\end{tabular}

Figures in parentheses represent total range unless indicated otherwise.

by autoimmune or toxic follicle destruction, pelvic surgery, radiation therapy, and other external factors [Maclaran and Panay, 2011]. However, POI has a significant genetic component, although the specific genetic cause is often not identified [Simpson and Rajkovic, 1999; BeckPeccoz and Persani, 2006; Woad et al., 2006; Nelson, 2009]. In addition, there are syndromic forms of POI, the most common of which is Turner syndrome due to monosomy X in complete or mosaic forms [Simpson and Rajkovic, 1999].

Chromosomal aberrations such as X chromosome deletions and translocations account for $5-10 \%$ of all cases with POI [Baronchelli et al., 2012]. Premutations of the $F M R 1$ gene on the $\mathrm{X}$ chromosome are overrepresented in patients with POI, with a POI incidence of $15-20 \%$ in premutation carriers [Saul and Tarleton, 1993; Wittenberger et al., 2007]. In comparison, the general population incidence of POI is 1\% [Coulam et al., 1986]. Approximately $2-5 \%$ of sporadic cases with POI can be explained by FMR1 premutations but so far are only described in patients with secondary amenorrhea [Wittenberger et al., 2007; De Vos et al., 2010]. Mutations in the genes encoding the transcription factors $N O B O X$ and FIGLA [Qin et al., 2007; Zhao et al., 2008], the oocyte secreted factors GDF9 and BMP15 [Dixit et al., 2006; Kovanci et al., 2007], and the hormone receptors FSHR and NR5A1 [Aittomaki et al., 1995; Janse et al., 2012] have also been found in patients with POI.

Recently, a novel candidate gene for POI has been identified by Zangen et al. [2011]. The authors describe a consanguineous family with several members affected by $46, \mathrm{XX}$ gonadal dysgenesis, a form of POI with primary amenorrhea and streak gonads. All affected patients shared a homozygous 3-bp deletion (c.600_602del,
p.Glu201del) in the PSMC3IP (PSMC3 interacting protein) gene detected by whole-exome sequencing. In cell line experiments, the mutant PSMC3IP protein exhibits a significantly decreased function as an estrogen co-activator. Estrogen is described to be important for primate prenatal development of the follicle pool as well as for the second stage of follicular development at puberty. Decreased estrogen-dependent transcription could possibly affect these developmental steps [Albrecht and Pepe, 2010; Zangen et al., 2011]. A defective function of PSMC3IP might therefore cause POI with either primary or secondary amenorrhea. Therefore, we have investigated our cohort of patients with POI for possible PSMC3IP mutations. To date, this is the first study to investigate the PSMC3IP gene in a group of unrelated patients with POI.

\section{Material and Methods}

\section{Patients}

Fifty cases selected among the patients referred to the Clinical Genetic Laboratory of Karolinska University Hospital Stockholm, Sweden were included in the study. The cohort consists of 23 patients with primary amenorrhea and 27 patients with secondary amenorrhea. Written informed consent was collected from all participants of age and from parents on behalf of minors included in the study. The regional Ethics Committee at Karolinska Institutet, Sweden approved the study and consent procedure.

The diagnosis of POI was established by the presentation of primary or secondary amenorrhea in individuals with female external genitalia as well as internal Müllerian structures (uterus) and hypergonadotropic hypogonadism $(\mathrm{FSH}>30 \mathrm{IU} / \mathrm{l})$ in at least 2 independent measurements. See table 1 for an overview of patients and clinical data.

Family history was negative for POI for all except 3 patients with secondary amenorrhea whose mothers also had menopause before 40 years of age. One patient with primary amenorrhea also has an affected sister with primary amenorrhea. Two patients within the cohort are related, paternal aunt and niece, with development of secondary amenorrhea at 34 and 22 years of age, respectively.

For all patients, previous surgery, chemotherapy, and radiotherapy were excluded. Five patients, 4 with secondary and 1 with primary amenorrhea, have hypothyroidism with anti-thyroid autoantibodies. None have antibodies against adrenal cortex or 21 -hydroxylase proteins. The 4 patients with secondary amenorrhea had debut of hypothyroidism after POI diagnosis. The patient with primary amenorrhea was diagnosed with anti-thyroid autoantibodies at 11 years of age.

Four patients with primary amenorrhea have been investigated with ovarian biopsies. These confirm streak gonads with no visible follicles. Five patients with secondary amenorrhea have also been investigated with ovarian biopsies, in 3 cases exhibiting streak gonads with no visible follicles. The 4th patient's biopsy showed multiple primordial follicles but no mature follicles. This patient pre- 
Table 2. Sequencing results

\begin{tabular}{|c|c|c|c|c|c|c|c|}
\hline SNP ID & $\begin{array}{l}\text { Minor allele } \\
\text { frequency }\end{array}$ & Location & Nucleotide change & $\begin{array}{l}\text { Amino } \\
\text { acid change }\end{array}$ & $\begin{array}{l}\text { Primary } \\
\text { amenorrhea (23) }\end{array}$ & $\begin{array}{l}\text { Secondary } \\
\text { amenorrhea (27) }\end{array}$ & Total (50) \\
\hline Novel change & - & intron 4 & NM_016556.3:c.337+33A>G & - & $\begin{array}{l}\text { A/A: } 23 \\
\text { A/G: } 0 \\
\text { G/G: } 0\end{array}$ & $\begin{array}{l}\text { A/A: } 26 \\
\text { A/G: } 1 \\
\text { G/G: } 0\end{array}$ & $\begin{array}{l}\text { A/A: } 49 \\
\text { A/G: } 1 \\
\text { G/G: } 0\end{array}$ \\
\hline rs75716493 & $C=0.018 / 40$ & intron 4 & NM_016556.3:c.338-101T>C & - & $\begin{array}{l}\text { T/T: } 23 \\
\text { T/C: } 0 \\
\text { C/C: } 0\end{array}$ & $\begin{array}{l}\text { T/T: } 26 \\
\text { T/C: } 1 \\
\text { C/C: } 0\end{array}$ & $\begin{array}{l}\text { T/T: } 49 \\
\text { T/C: } 1 \\
\text { C/C: } 0\end{array}$ \\
\hline rs2292752 & $\mathrm{G}=0.465 / 1015$ & intron 4 & NM_016556.3:c.338-15C>G & - & $\begin{array}{l}\mathrm{C} / \mathrm{C}: 5 \\
\mathrm{C} / \mathrm{G}: 10 \\
\mathrm{G} / \mathrm{G}: 8\end{array}$ & $\begin{array}{l}\mathrm{C} / \mathrm{C}: 3 \\
\mathrm{C} / \mathrm{G}: 13 \\
\mathrm{G} / \mathrm{G}: 11\end{array}$ & $\begin{array}{l}\mathrm{C} / \mathrm{C}: 8 \\
\mathrm{C} / \mathrm{G}: 23 \\
\mathrm{G} / \mathrm{G}: 19\end{array}$ \\
\hline
\end{tabular}

sented with secondary amenorrhea at 23 years of age. The 5 th patient had a few visible primordial and primary follicles and presented with secondary amenorrhea at 15 years of age.

\section{Genetic Investigation}

DNA was extracted from peripheral blood leukocytes or from EBV-transformed lymphocytes. A 46,XX karyotype in peripheral blood was confirmed in all but in patient 24 in whom a balanced Robertsonian translocation was identified (45,XX,der(13;14)), not considered causative. Sex chromosome mosaicism was excluded using fluorescence in situ hybridization (FISH) and DNA probes from chromosome $\mathrm{X}$ and $\mathrm{Y}$ on peripheral blood smears and, when available, on touch preparations from gonadal tissue. Genetic investigation included sequencing of NR5A1, BMP15, FSHR, NOBOX, and GDF9. FMR1 mutations were also excluded in patients with secondary amenorrhea.

\section{Control Material}

As control material DNA samples were prepared from peripheral blood lymphocytes of 95 healthy women. All were above the age of 40 years at sample collection and had given birth to at least 1 child. Exclusion criteria for participation were previous egg donation, in vitro fertilization, fertility treatment, or menopause before the age of 40 years.

\section{PCR and Sequencing}

The 8 exons and all exon-intron boundaries of the PSMC3IP gene were amplified by PCR and sequenced. Primers were designed using Primer 3 software (v3.0.0, http://primer3.wi.mit. edu/) [Koressaar and Remm, 2007; Untergasser et al., 2012]. See online supplementary table 1 (for all online suppl. material, see www.karger.com/doi/10.1159/000357605) for primer sequences. PCR conditions are available on request.

PCR products were cleaned with Exonuclease 1 and Shrimp Alkaline Phosphatase (Thermo Scientific, Fermentas, St.Leon-Rot, Germany) and sequenced using the ABI BigDye Terminator v3.1 kit (Applied Biosystems, Life Technologies Europe BV, Stockholm, Sweden) according to the manufacturers' instructions. Fragments were separated on a 3730 DNA Analyzer (Applied Biosystems). Electropherograms were analyzed against the reference sequence NG_031960.1 using the SeqScape v2.5 program (Applied Biosystems).
Statistical Analysis

Binomial parameters were calculated using StatXact 4,CYTEL Software corporation (Cambridge, USA). A 95\% confidence interval was calculated according to Clopper-Pearson.

\section{In silico Analysis}

The analysis of splicing efficiency for the novel variant as well as the normal sequence was carried out using 3 different splice site prediction tools: The Splice Site Prediction by Neural Network tool from the Berkeley Drosophila Genome Project (http://www.fruitfly.org/seq_tools/splice.html); NetGene2 v. 2.4 (http://www.cbs. dtu.dk/services/NetGene2/); FSPLICE 1.0 (http://linux1.softberry.com/berry.phtml? topic $=$ fsplice \& group $=$ programs \&sub group=gfind).

\section{Results}

Samples from all 50 patients were successfully sequenced. No mutations or sequence variations in the coding region of the PSMC3IP gene were detected. In intron 4 , a novel heterozygous change was identified in 1 patient with secondary amenorrhea at 37 years of age which was not detected in any of the 190 control alleles investigated. The transition NM_016556.3:c.337+33A $>$ G has not been previously reported. In addition, 2 single nucleotide polymorphisms were found, rs75716493 and rs2292752, presenting at a frequency concordant with the reported minor allele frequency. See table 2 for sequencing results.

\section{Discussion}

POI, characterized by hypergonadotropic hypogonadism, can present with primary amenorrhea, or more commonly with secondary amenorrhea before 40 years of age. $\mathrm{POI}$ is heterogeneous and has several described causative 
genetic mechanisms, both at the chromosomal and single gene level. Still, the majority (90\%) of patients with POI does not receive a molecular diagnosis [Nelson, 2009], and many involved genes are still unknown.

The most common known single gene cause of POI is an FMR1 premutation, with a detection rate between $2-5 \%$ in sporadic cases and up to $13 \%$ in familial cases [Wittenberger et al., 2007; De Vos et al., 2010]. A French study reported a high mutation frequency $(6.2 \%)$ in the NOBOX gene in a cohort of patients with POI [Bouilly et al., 2011]. Mutations in other genes, such as FSHR, $B M P 15$, and GDF9, have so far only been described in a limited number of cases with POI [Aittomaki et al., 1995; Di Pasquale et al., 2004; Zhao et al., 2007; Lakhal et al., 2010].

The PSMC3IP protein binds to the alpha- and betaestrogen receptors as well as the glucocorticoid, thyroid, androgen, and progesterone receptors and acts as a coactivator of hormonally dependent transcriptional activation [Ko et al., 2002]. It is therefore an interesting candidate gene for ovarian function and development and has been proposed as a novel candidate gene for POI by Zangen et al. [2011]. In this study, a decreased transcriptional activity was reported for the mutant PSMC3IP protein in cell lines, supporting its possible causative role. The described homozygous c.600-602del mutation could, however, not be detected in any of the samples in our study, nor was any other mutation in the coding region of the PSMC3IP gene discovered. In intron 4, a previously unreported variant, NM_016556.3:c.337+33A>G, was detected in heterozygous form in a single patient with secondary amenorrhea. In silico analysis of splicing efficiency using 3 different prediction tools did not support an effect of the variant on splicing. Although we could not detect this change in any of the 190 control alleles investigated, it is most likely to constitute a rare normal variant.

POI is a severe condition affecting approximately $1 \%$ of women, and for each new candidate gene it is important to investigate the possible frequency of pathogenic mutations in patients with POI. This should be done both for diagnostic purposes and for strengthening the understanding of gene function in ovarian development and maintenance. The PSMC3IP gene has so far only been investigated in a single consanguineous family with hereditary POI. The present study is based on a group of 50 patients with POI and primarily Swedish Caucasian ethnic background, where no mutation of the PSMC3IP gene was detected. Using binomial probability calculation, we can note that the probability of detecting mutations in 0 out of 50 patients with POI with an assumed POI population prevalence of possible causative PSMC3IP mutations of $5.8 \%$ is only $5 \%$ (exact confidence interval $0-7.11 \%$ ). This is less than reported for mutations in the autosomal gene NOBOX in Caucasian patients with POI and some reported studies of FMR1 premutations. Therefore, we can conclude that PSMC3IP gene mutations are not a common cause of POI in this Swedish cohort. Conversely, to detect a PSMC3IP mutation prevalence of $1.5 \%$, i.e. below the prevalence of FMR1 premutations, with the same $5 \%$ probability, a sample size of 200 patients would be necessary, larger than any reported single gene study for POI.

Our patients are mostly Swedish, whereas the family investigated by Zangen et al. [2011] was of Palestinian descent. It remains possible that the discovered mutation can be found in a higher prevalence in patients of this ethnic background. For comparison, FSHR mutations are primarily found in the Finnish population [Aittomaki et al., 1995; Conway et al., 1999], and the aforementioned NOBOX mutations have been detected in Caucasians but could not be found in a large group of Chinese women [Qin et al., 2007, 2009; Bouilly et al., 2011]. In addition to the population differences, causative mutations have so far mostly been described only in a small number of cases each, indicating that there is a large degree of heterogeneity in POI. Thus, several unknown genes most likely remain to be identified. It is also possible that there could be synergistic effects with combinations of gene variants causing the phenotype.

For clinical genetic investigation of POI, a single gene approach with consecutive screening by conventional sequencing of candidate genes has so far been quite unsuccessful and expensive, with a low detection rate per gene investigated. With the development of next-generation sequencing techniques, a multiple gene approach where a panel of known candidate genes is analyzed simultaneously, screening could be more successful. Whole-exome sequencing can also be considered, with proper caution concerning interpretation of unknown variants. Also, as many developmentally important genes act in a dosage dependent manner, array-CGH could be another useful tool for the identification of both known causes and novel candidate genes for POI. In the future, whole-genome sequencing may allow the simultaneous detection of gene dosage aberrations and small DNA sequence aberrations, hopefully improving diagnostics and knowledge on pathogenetic mechanisms for this group of patients. 


\section{Acknowledgements}

The study was supported by grants from the Swedish Research council (project No. 12198 to A.W., and project No. 20324 to A.L.H.), Stockholm County Council (E.I., A.W., K.A.R.-W.), Foundation Frimurare Barnhuset (A.N., A.W., M.B.), Karolinska Institutet (A.N., A.L.H., E.I., A.W., M.B.), Novo Nordic Foundation (A.W.), and Svenska Läkaresällskapet (M.B.). The funding sources had no involvement in the study.
We thank Johan Svensson (Dept. of Child and Adolescent Medicine, Skåne University Hospital, Malmö, Sweden) for contributing to patient samples and clinical characterization, and Elisabeth Berg (Dept. of Learning, Informatics, Management and Ethics, Karolinska Institute, Stockholm, Sweden) for contributing to statistical analysis and interpretation.

\section{References}

Aittomaki K, Lucena JL, Pakarinen P, Sistonen P, Tapanainen J, et al: Mutation in the folliclestimulating hormone receptor gene causes hereditary hypergonadotropic ovarian failure. Cell 82:959-968 (1995).

Albrecht ED, Pepe GJ: Estrogen regulation of placental angiogenesis and fetal ovarian development during primate pregnancy. Int J Dev Biol 54:397-408 (2010).

Baronchelli S, Villa N, Redaelli S, Lissoni S, Saccheri $\mathrm{F}$, et al: Investigating the role of $\mathrm{X}$ chromosome breakpoints in premature ovarian failure. Mol Cytogenet 5:32 (2012).

Beck-Peccoz P, Persani L: Premature ovarian failure. Orphanet J Rare Dis 1:9 (2006).

Bouilly J, Bachelot A, Broutin I, Touraine P, Binart N: Novel NOBOX loss-of-function mutations account for $6.2 \%$ of cases in a large primary ovarian insufficiency cohort. Hum Mutat 32:1108-1113 (2011)

-Conway GS, Conway E, Walker C, Hoppner W, Gromoll J, Simoni M: Mutation screening and isoform prevalence of the follicle stimulating hormone receptor gene in women with premature ovarian failure, resistant ovary syndrome and polycystic ovary syndrome. Clin Endocrinol (Oxf) 51:97-99 (1999).

Coulam CB, Adamson SC, Annegers JF: Incidence of premature ovarian failure. Obstet Gynecol 67:604-606 (1986).

De Vos M, Devroey P, Fauser BC: Primary ovarian insufficiency. Lancet 376:911-921 (2010).

Di Pasquale E, Beck-Peccoz P, Persani L: Hypergonadotropic ovarian failure associated with an inherited mutation of human bone morphogenetic protein-15 (BMP15) gene. Am J Hum Genet 75:106-111 (2004).
Dixit H, Rao LK, Padmalatha VV, Kanakavalli M, Deenadayal M, et al: Missense mutations in the $B M P 15$ gene are associated with ovarian failure. Hum Genet 119:408-415 (2006).

-Janse F, de With LM, Duran KJ, Kloosterman WP, Goverde AJ, et al: Limited contribution of NR5A1 (SF-1) mutations in women with primary ovarian insufficiency (POI). Fertil Steril 97:141-146 e142 (2012)

Ko L, Cardona GR, Henrion-Caude A, Chin WW: Identification and characterization of a tissue-specific coactivator, GT198, that interacts with the DNA-binding domains of nuclear receptors. Mol Cell Biol 22:357-369 (2002).

Koressaar T, Remm M: Enhancements and modifications of primer design program primer3. Bioinformatics 23:1289-1291 (2007).

Kovanci E, Rohozinski J, Simpson JL, Heard MJ, Bishop CE, Carson SA: Growth differentiating factor-9 mutations may be associated with premature ovarian failure. Fertil Steril 87: 143-146 (2007).

Lakhal B, Laissue P, Braham R, Elghezal H, Saad A, et al: BMP15 and premature ovarian failure: causal mutations, variants, polymorphisms? Clin Endocrinol (Oxf) 72:425-426 (2010).

Maclaran K, Panay N: Premature ovarian failure. J Fam Plann Reprod Health Care 37:35-42 (2011).

Nelson LM: Clinical practice. Primary ovarian insufficiency. N Engl J Med 360:606-614 (2009).

Qin Y, Choi Y, Zhao H, Simpson JL, Chen ZJ, Rajkovic A: NOBOX homeobox mutation causes premature ovarian failure. Am J Hum Genet 81:576-581 (2007).

Qin Y, Shi Y, Zhao Y, Carson SA, Simpson JL, Chen ZJ: Mutation analysis of NOBOX homeodomain in Chinese women with premature ovarian failure. Fertil Steril 91:1507-1509 (2009).
Saul RA, Tarleton JC: FMR1-related disorders, in Pagon RA, Bird TD, Dolan CR, Stephens K, Adam MP (eds): GeneReviews ${ }^{\mathrm{TM}}$ [Internet]. (University of Washington, Seattle 1993). http://www.ncbi.nlm.nih.gov/books/ NBK1384/

Simpson JL, Rajkovic A: Ovarian differentiation and gonadal failure. Am J Med Genet 89:186200 (1999).

Untergasser A, Cutcutache I, Koressaar T, Ye J, Faircloth BC, et al: Primer3 - new capabilities and interfaces. Nucleic Acids Res 40:e115 (2012).

Wittenberger MD, Hagerman RJ, Sherman SL, McConkie-Rosell A, Welt CK, et al: The FMR1 premutation and reproduction. Fertil Steril 87:456-465 (2007)

-Woad KJ, Watkins WJ, Prendergast D, Shelling AN: The genetic basis of premature ovarian failure. Aust N Z J Obstet Gynaecol 46:242244 (2006).

-Zangen D, Kaufman Y, Zeligson S, Perlberg S, Fridman $\mathrm{H}$, et al: $\mathrm{XX}$ ovarian dysgenesis is caused by a PSMC3IP/HOP2 mutation that abolishes coactivation of estrogen-driven transcription. Am J Hum Genet 89:572-579 (2011).

Zhao H, Qin Y, Kovanci E, Simpson JL, Chen ZJ, Rajkovic A: Analyses of GDF9 mutation in 100 Chinese women with premature ovarian failure. Fertil Steril 88:1474-1476 (2007).

Zhao H, Chen ZJ, Qin Y, Shi Y, Wang S, et al: Transcription factor FIGLA is mutated in patients with premature ovarian failure. Am J Hum Genet 82:1342-1348 (2008). 